\title{
Technologies and Technical Means for Anti- Erosion Differentiated Soil Treatment System
}

\author{
Bakhadir Mirzaev ${ }^{1 *}$, Farmon Mamatov ${ }^{2}$, Ikromjon Avazov $^{1}$ and Sherzod Mardonov ${ }^{1}$ \\ ${ }^{1}$ Tashkent Institute of Irrigation and Agricultural Mechanization Engineers, 100000Tashkent, \\ Uzbekistan \\ ${ }^{2}$ Karshi Engineering Economic Institute, 180100 Karshi, Uzbekistan
}

\begin{abstract}
This paper highlights the necessity of system modification of the main soil slopes processing by developing new technologies of processing eroded soils and technical means to protect a soil from wind and water erosion, reduce processing energy costs, improve moisture accumulation and preservation, and increase the aggregate productivity. An improved differentiated system of slopes soil tilling is proposed, including a crest-stepped ploughing with complete alternation (at $180^{\circ}$ within the range of own furrow) and incomplete turnover of the layers and mouldboardless two-tier tilling. During the first year, a crest-stepped ploughing was carried out on slope fields affected by water and wind erosion. Thus, stratum's subsurface layers are strip loosened. To implement this technology, an improved plough for crest-stepped ploughing developed on the basis of a stepped plough for furrowless smooth tillage is proposed. The rotation was carried out with mould boardless two-tier soil tilling by a ripper with inclined posts. Further, it is recommended to develop and implement combined machines able to simultaneously conduct mould boardless and mouldboard soil tilling, strip subsurface loosening, fertilizer application and other manipulations to prepare soil for sowing and the sowing per one passage of the unit to protect soil from wind and water erosion.
\end{abstract}

\section{Introduction}

A systematic land ploughing and intensification of agriculture especially on slopes, leads to an increase in the proportion of areas undergoing erosion. Water erosion and lack of soil moisture on the slopes of rainfed lands is one of the serious problems. In our republic, rainfed agricultural lands suitable for agriculture comprise 2 million 130 thousand hectares $[1,2]$, of which 756.8 thousand hectares is arable land. More than $70 \%$ of the cultivated area of rainfed lands is subjected to varying degrees of wind and water erosion.

From the analysis of research and development studies, it has been established that the most effective method of anti-erosion soil tillage is flat tillage. However, reclining, along with the positive aspects, has its drawbacks. For instance, it does not provide effective weed control, which leads to the gradual clogging of fields. Widely used basic tillage with

\footnotetext{
Corresponding author: bahadir.mirzaev@bk.ru
} 
reversible-dumping plows as well as the most important advantages, such as effective weed control and good loosening of the soil, has several disadvantages: high energy intensity of the ploughing process, inappropriate use on soils subject to wind erosion and the possibility of plow sole formation [3].

Therefore, many researchers recommend differentiating tillage. Differentiation of the arable layer of soil was founded by V.R. Williams [6]. He argues that for the soil-forming process it is necessary to leave the top layer of soil under the vegetation cover for two to three years. MG Chizhevsky, D.I. Popazov, V.V. Kvasnikov, Ya.N.Mukhortov, V. I. Rumyantsev [7, 8] indicated the need for alternating deep ploughing with surface treatments on different soils.

Scientists from The University of Mordovia [4] used an alternating loosening of 30-32 $\mathrm{cm}$ with ploughing (depth of 20-22 $\mathrm{cm}$ ) to absorb moisture on eroded soils and increase yields. They found that this alternation reduced the soil washout by 1.99 times, increasing barley yield by $28 \%$ compared with annual ploughing at $20-22 \mathrm{~cm}$ across the slope. According to the research results, they believe that there is no need for annual deep ploughing in order to reduce surface water effluent and soil flush on the slopes.

To combine the advantages of traditional ploughing and minimum soil-free tillage, scientists from the Research Institute of Agricultural Mechanization [3] offer a treatment system that includes the following technological operations: rotations on the field surface in the first year, released from under perennial grasses, the necessary amount of organic fertilizers are scattered on the field surface, then ploughing is carried out with a full (by $180^{\circ}$ ) layer reversal with plows, equipped with screw piles, or with two-tier ploughing plows. In subsequent years, the rotation is carried out pre-sowing surface tillage (loosening without turning) by means of disc, cultivator, chisel and other loosening working bodies. According to their experiments on the flat lands, the contamination of crops is reduced by 3-4 times, for the rotation, the total energy and labour costs are reduced by 1.5-2 times.

Kh.M.Makhsudov and S.S. Rustamov [5] recommended a production which is based on the application of antidumping tillage with flat-cutters and heavy harrows (BDT-3) alternating with traditional dumping tillage (depth of $2022 \mathrm{~cm}$.) in order to protect dark gray terrestrial soils from water erosion to preserve the deficit-free balance of humus and the main plant nutrients. They indicate that active weed control should be used on winter wheat crops in the years of alternation of small, antidumping treatments of rainfed dark serozems with dump ploughing by $20-22 \mathrm{~cm}$.

Existing differentiated tillage systems were carried out by traditional technical means that are not sufficiently effective in the treatment of soils subject to wind and water erosion. Since, these tools are not perfect enough and have a number of drawbacks; existing dump guns loosen the soil to the same depth. As a result, when tilling the soil with existing rippers, the small ridges formed at the bottom of the furrow do not allow holding and accumulating rainwater after heavy rainfall which leads to water erosion. The technological process of improved conventional standard plows for the soils prone treatment resistant to water erosion is based on rolling the soil layers to the side (into the next furrow), which leads to the formation of wide break-up furrows and high open furrows, as well as displacement of the soil along the slope up or down by 50-60 cm. In addition, they carry out ploughing in a driven way which leads to a sharp decrease in productivity and quality of work on sloping lands.

From the above, it was necessary to improve the differentiated system of soil treatment, which would ensure effective protection of soil from wind and water erosion, reduction of weed infestation, increase in labor productivity and minimal costs for tillage. 


\section{Research Methods}

The work was carried out using the basic principles and methods of classical mechanics, mathematical and statistics, methods of mathematical planning of the experiment and general methods for determining the machines' agrotechnical, energy and economic performance.

\section{Results and Discussions}

To protect the soil of slopes from wind and water erosion, we proposed an improved differentiated tillage system, which includes the following technologies and technical means. During the first year, on the slope fields prone to water erosion, there is a ridge-step ploughing with alternating full (at $180^{\circ}$ within its own furrow) and incomplete turnover of the layers (Fig. 1). At the same time, the subsurface soil layers are loosened. To implement this technology, an improved plow for ridge-step ploughing is proposed on the basis of a step plow for easy and smooth ploughing [9]. In the following year, rotation is carried out without tail two-tier tillage (Fig. 2) with a cultivator with inclined stands [10]. At the same time, the depth of loosening and the distance between the loosened strips is determined based on the soil and climatic conditions. The alternation of ridge-step ploughing and bottomless two-tier tillage depends on the state of the field, soil and climatic conditions.

According to the results from theoretical and experimental studies, a two-tier ripper with working bodies with an inclined stand was developed and its production tests was carried out [11].

The results of agrotechnical assessment showed that the ripper on the stability of the tillage depth, soil surface ridging, stubble conservation and the content of erosivehazardous particles shows the best performance compared with existing tools. When a twostage ripper is operating in a layer of $0-5 \mathrm{~cm}$, the number of erosive-hazardous particles decreases 2.07 times. Experimental ripper compared with the base machine has $18.3 \%$ higher performance and accordingly, lower specific fuel consumption [11].

Based on the results from theoretical and experimental studies, the following constructions of prototypes of the plow for smooth-step ploughing were made [11]: 1 - a double-hulled plow with bodies with different rack heights; 2 - a two-part plow with two submersible tillers mounted on bodies with the same height; 3 - the same plow with one subsoiler mounted on an even hull with a long hedge. A short hedgehog was installed on the odd hull of these plows. At the same time, a subsoiler with an inclined stand like "paraglider" was installed for loosening the subsurface horizon on the plow [11].

The results of experimental studies of plows' prototypes showed that they are not significantly different in their basic quality indicators [11]. After their passage, a ridge surface and a stepped bottom of the ramp are formed. The greatest ridge surface of arable land is obtained when the plow is working with hulls of different heights. However, this decreases a depth and degree of embedding of plant residues compared with other options. This is obviously due to the fact that with an increase in the depth of treatment a layer turnover is worsened by an even hull. It was then established that a plow with a subsoiler submersible installed behind an even hull has advantages compared with the first and second variants in terms of tractive resistance, respectively, by $11.88 \%$ and $7.9 \%$, in terms of stability and metal content [11].

An analysis from the basic law of development and patent research, as well as trends in the development of machines for processing and preparing the soil, shows that in the near future, to save the soil from wind and water erosion, it is possible to develop and create combined machines capable of producing soil-free or waste-free soil treatment, lined 
subsoil loosening, fertilization, preparing the soil for sowing and sowing in one pass of the unit [12].

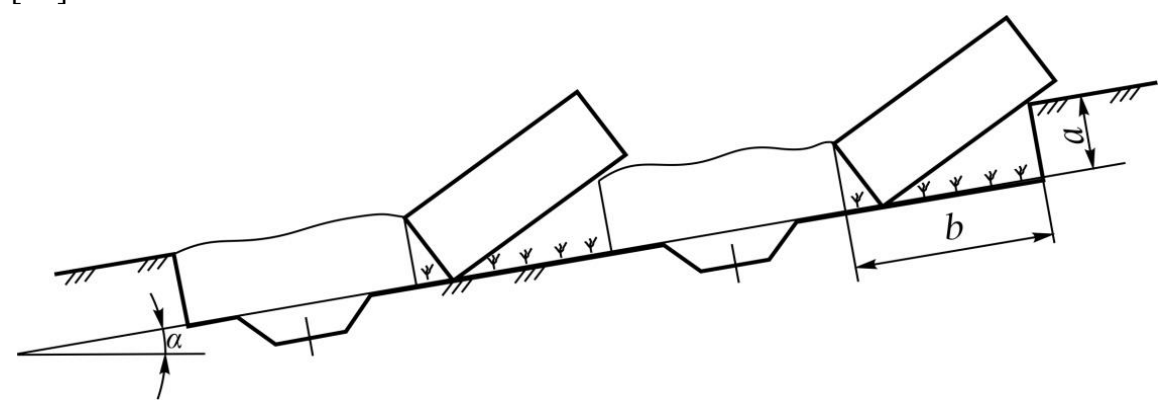

Fig.1. Cross-section of arable land after the plow passage for ridge-step ploughing with subsoilers



Fig.2. A technological process of the two-tier ripper: 1 - frame; 2 - upper tier ripper; 3 - lower tier ripper; 4 - stand; 5 - a knife; 6 - chisels; 7 - field board; 8 - plate

\section{Conclusions}

1. Protection of soil slopes from wind and water erosion, improvement of quality indicators of primary tillage, reduction of its energy intensity can be achieved through the introduction of an improved differentiated tillage system, including a new technology of ridge-graded ploughing based on smooth, plow-free ploughing and two-tier soil processing.

2. A promising direction of soil conservation from wind and water erosion is the development and creation of combined machines capable of simultaneously performing antidumping and dumping soil treatment, lined subsoil loosening, fertilization and other soil preparation for planting and sowing in one pass of the unit.

\section{References}

1. M.M. Nasriddinov, M.B. Khamraev, M.R. Nasriddinov, The intensification of the use of desert soils, MEHNAT, pp.102 (1989)

2. H.M. Makhsudov, Soil erosion and arid zones in Uzbekistan, FAN, pp. 168 (1989)

3. O.A. Sizov, The effectiveness of energy-saving system the basic of soil cultivation in crop and conservation tillage (zero-tillage) combine, Collection of Scientific Papers VIM, Moscow, pp. 86-93 (1989)

4. G.G. Danilov, I.F. Kargin, N.S. Nemsov, Tillage system, Rosselkhozizdat, pp. 270 (1982)

5. S.S. Rustamov, Influence of ways, tillage depth and fertilization rates on wheat yield under rain-fed, dark gray soils eroded, Diss. cand. farming. Sciences, UzSRIC, pp. 27 (2004)

6. V.R.Williams, Soil science, The basics of soil science, pp. 104-171 (1940) 
7. M.G. Chizhevsky, M.G. Avaev, Agriculture with the basics of soil science, State publishing of agricultural literature, pp.431 (1953)

8. Y.N. Mukhortov, Influence of ways of black soil tillage on yield of winter wheat, Questions tillage, pp.68-87 (1953)

9. Patent RUz FAP N 00863, Plough, M.F. Mamatov, B.S. Mirzaev, Official bulletin, 1 (2014)

10. Patent RUz FAP N 00701, The plow-ripper, M.F. Mamatov, B.S. Mirzaev, Official bulletin, 3 (2012)

11. B.S. Mirzaev, Improvement of technologies and technical means for anti-erosion tillage in the conditions of Uzbekistan, Diss. d.tech.sci., pp. 200 (2015)

12. Patent RUzFAP N 00657, Combined instrument for tillage and seeding, M.F. Mamatov, B.S. Mirzaev, Official bulletin, 11 (2011) 